\title{
Mathematical modeling of a multi-product EMQ model with an enhanced end items issuing policy and failures in rework
}

\author{
Yuan-Shyi Peter Chiu', Peng-Cheng Sung ${ }^{1}$, Singa Wang Chiu ${ }^{2}$ and Chung-Li Chou ${ }^{2 *}$
}

${ }^{*}$ Correspondence: echungc@cyut.edu.tw

${ }^{2}$ Department of Business Administration, Chaoyang University of Technology, Taichung 413, Taiwan Full list of author information is available at the end of the article

\begin{abstract}
This study uses mathematical modeling to examine a multi-product economic manufacturing quantity $(E M Q)$ model with an enhanced end items issuing policy and rework failures. We assume that a multi-product EMQ model randomly generates nonconforming items. All of the defective are reworked, but a certain portion fails and becomes scraps. When rework process ends and the entire lot of each product is quality assured, a cost reduction $n+1$ end items issuing policy is used to transport finished items of each product. As a result, a closed-form optimal production cycle time is obtained. A numerical example demonstrates the practical usage of our result and confirms a significant savings in stock holding and overall production costs as compared to that of a prior work (Chiu et al. in J Sci Ind Res India, 72:435-440 2013) in the literature.
\end{abstract}

Keywords: Mathematical modeling, Optimization, Multi-product system, Economic manufacturing quantity, Multi-delivery, Rework failures

\section{Background}

Mathematical modeling is used in this study to examine a multi-product EMQ model with rework failures and an enhanced cost reduction end items issuing policy. The EMQ model made use of a mathematical technique to balance the setup and holding costs incurred in a production cycle, and derive most economic manufacturing quantity that minimizes the long run average system costs per unit time (Taft 1918). The assumption of traditional EMQ model includes a perfect manufacturing process for a single product, and a continuous finished product distribution policy. Although the assumptions of the EMQ model are simple and somehow unrealistic, its concept along with solution procedure has since been extensively applied to the fields of inventory control and production management (Hadley and Whitin 1963; Silver et al. 1998; Nahmias 2009; Battini et al. 2010a; Andriolo et al. 2014; Azzi et al. 2014; Glock et al. 2014). In order to increase machine utilization, the vendors in manufacturing sector often fabricate multiple products in sequence on a single machine. Rosenblatt and Finger (1983) considered a single machine multi-item production problem, whereas the machine was an electrochemical machining system, and its outputs are impact sockets of different sizes for power wrenches. They used a grouping procedure for various different products along with a modified version of an existing algorithm to confirm that the cycle times are the

(c) 2015 Chiu et al. This article is distributed under the terms of the Creative Commons Attribution 4.0 International License (http:// creativecommons.org/licenses/by/4.0/), which permits unrestricted use, distribution, and reproduction in any medium, provided you give appropriate credit to the original author(s) and the source, provide a link to the Creative Commons license, and indicate if changes were made. 
multiples of the shortest cycle time. Federgruen and Katalan (1998) examined stochastic economic batch scheduling problems with periodic base-stock policies, where all products are fabricated according to a given periodic item-order. They proposed some effective heuristics to minimize system-wide costs for such a periodic item-sequence production. Muramatsu et al. (2013) studied a multi-item multi-process dynamic lot size scheduling problem with setup time and general product structure. Various heterogeneous decision features such as lot sizing, lot sequencing, dispatching are considered. A near-optimal solution procedure was proposed to determine the decision features involved in this problem simultaneously. Caggiano et al. (2009) proposed a method for computing the channel fill rates in a multi-product, multi-echelon service parts distribution system. A simulation approach was employed to study multi-item three-echelon production- distribution system. They showed that the estimation errors are insignificant over a wide range of base stock level vectors and they also presented an enhanced approximation method to the problem. Jodlbauer and Reitner (2012) investigated a stochastic make-to-order multi-product manufacturing system under a common cycle policy. Effects of the safety stock, demand, cycle time, and setup time on the service level and on the total system costs were investigated. Papers that related to various aspects of planning and optimization issues on multi-item production can also be referred to Lin et al. (2014); Wu et al. (2014).

In real manufacturing environments, due to unpredictable factors production of defective products is inevitable. Sometimes, certain portion of nonconforming products can be reworked and repaired with additional repair expense. Agnihothri and Kenett (1995) studied the effects of defects on various system performance measures for a manufacturing process with rework. They offered management guidelines for allocating additional budget in process improvement for continuously increasing yield rate, identifying potential bottlenecks under increasing workloads, and providing extra resources to release bottlenecks. Extra studies that addressed various aspects of specific features including imperfect quality production and the rework processes can also be found elsewhere (Grosfeld-Nir and Gerchak 2002; Biswas and Sarker 2008; Battini et al. 2010b; Glock 2011a, 2012a; Chiu and Chang 2014; Wee et al. 2014; Murugan and Selladurai 2014; Hishamuddin et al. 2014; Battini et al. 2014; Chiu et al. 2014). The conventional EMQ model assumes a simplified 'continuous product issuing policy'. However, in real supply chains environments multiple or periodic product delivery policy is commonly adopted. Banerjee (1986) examined a joint economic lot-size model for vendor and buyer, with the focus on minimizing the total joint relevant cost. He concluded that a jointly optimal ordering policy along with an appropriate price adjustment, could be economically beneficial for both buyer and vendor. Swenseth and Godfrey (2002) revealed that the freight rate functions can be combined into inventory replenishment decisions without lowering the accuracy of decisions, nor will these functions increase the complexity of the decision making process. Abdul-Jalbar et al. (2008) studied a one-vendor multibuyer multi- echelon finite production rate system. The objectives of their study are to determine the optimal production and shipment schedule, and the most economic order size for buyers so that average total cost per unit time can be minimized. In a recent study, Chiu et al. (2013) determined optimal common production cycle time for a multiitem production system with discontinuous $n$ fixed quantity multiple delivery policy 
and rework failures. Mathematical modeling and optimization techniques are employed in their study to solve the problem. As a result, a closed-form optimal common cycle time that minimizes the expected system costs is obtained. Effect of rework failure on the optimal cycle time was investigated through a numerical example. Additional studies that addressed various aspects of periodic or multi-delivery issues of vendor-buyer integrated systems can be referred to (Glock 2011b, 2012b; Katsaliaki et al. 2014; Safaei 2014; Rodger 2014; Sana et al. 2014).

For the purpose of lowering producer's inventory holding cost as well as minimizing the expected overall system cost, we extend Chiu et al's (2013) work by replacing their $n$ fixed quantity end items delivery policy with an enhanced $n+1$ issuing policy. Under the new policy, one extra delivery of end items is made in producer's production uptime to satisfy customers' demands during production uptime and rework time. Then, upon completion of the rework, additional $n$ installments (fixed quantity) of end items are shipped at a fixed time interval. The objectives of this study are to determine optimal common cycle time that minimizes the long-run average system cost per unit time, and investigate effects of random defective rate, rework failures, and the enhanced end items issuing policy on the optimal operating cycle time as well as on the expected system costs per unit time.

\section{Problem description and mathematical modeling}

We use mathematical modeling to examine a multi-product EMQ system with a cost reduction multi-distribution policy and rework failures. Consider there are $L$ products to be fabricated in sequence on a single machine and there is a $x_{\mathrm{i}}$ portion of nonconforming items being randomly produced at a rate $d_{1 \mathrm{i}}$ during the production of product $i$ (where $i=1,2, \ldots, L$ ). All items are screened and cost of quality inspection is included in unit production $\operatorname{cost} C_{i}$. Under the normal operation (which shortage are not permitted), the constant production rate $P_{1 \mathrm{i}}$ for product $i$ must satisfies $\left(P_{1 \mathrm{i}}-d_{1 \mathrm{i}}-\lambda_{\mathrm{i}}\right)>0$, where $\lambda_{\mathrm{i}}$ denotes demand rate for product $i$ per year, and $d_{1 \mathrm{i}}=x_{\mathrm{i}} P_{1 \mathrm{i}}$. All nonconforming items are reworked at a rate of $P_{2 \mathrm{i}}$ each cycle immediately following the end of regular production process. The additional rework cost is $C_{\mathrm{Ri}}$ per item. A failure-in-rework rate $\phi_{\mathrm{i}}$ exists during the reworking process, the production rate of scrap items during rework $d_{2 \mathrm{i}}=\phi_{\mathrm{i}} P_{2 \mathrm{i}}$, and those that fail in repair are discarded at a unit disposal cost $C_{\mathrm{Si}}$. A specific $n+1$ multi-shipment policy is proposed in an attempt to reduce the vendor's stock holding cost as compared to $n$ multi-delivery policy used in Chiu et al. (2013). Under the proposed $n+1$ delivery policy, the purpose of the first shipment of finished goods is to meet buyers' product demands during vendor's uptime and reworking time. Then upon completion of rework process, $n$ fixed quantity installments of the end items are distributed to buyers at a fixed time interval $t_{\mathrm{n}}$ (see Fig. 1).

Figure 2 depicts producer's on-hand inventory level of perfect quality items of product $i$ in the proposed $n+1$ delivery model (in blue lines) and the expected reduction in vendor's stock holding costs (yellow shaded area) in comparison with that of Chiu et al. (2013). Cost related variables used in our analysis comprise the setup cost $K_{i}$ per cycle, unit holding $\operatorname{cost} h_{i}$, unit holding $\operatorname{cost} h_{1 i}$ during rework, the fixed shipping cost $K_{1 i}$ for product $i$ per delivery, and unit shipping $\operatorname{cost} C_{\mathrm{T} i}$ for each product $i$. Additional variables also include the following: $T=$ common production cycle length, our decision variable, $Q_{i}=$ batch size per cycle for product $i, n=$ number of installments (fixed 


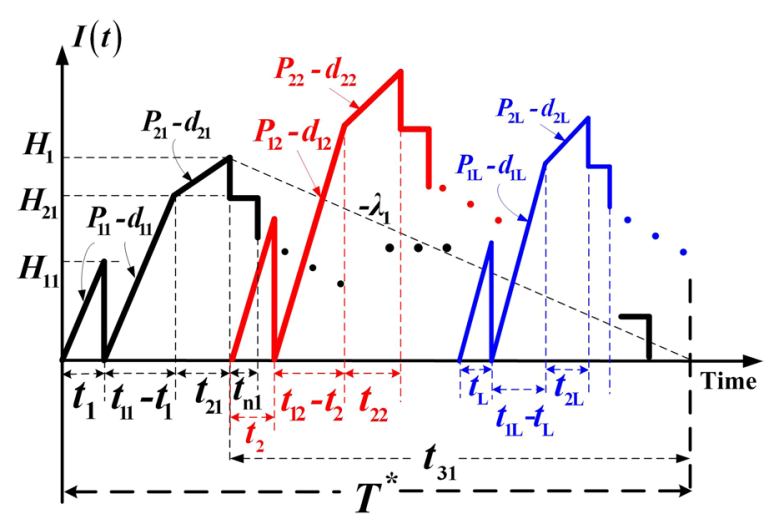

Fig. 1 On-hand inventory of perfect quality items in the proposed multi-item production system with rework failures and a cost reduction distribution policy

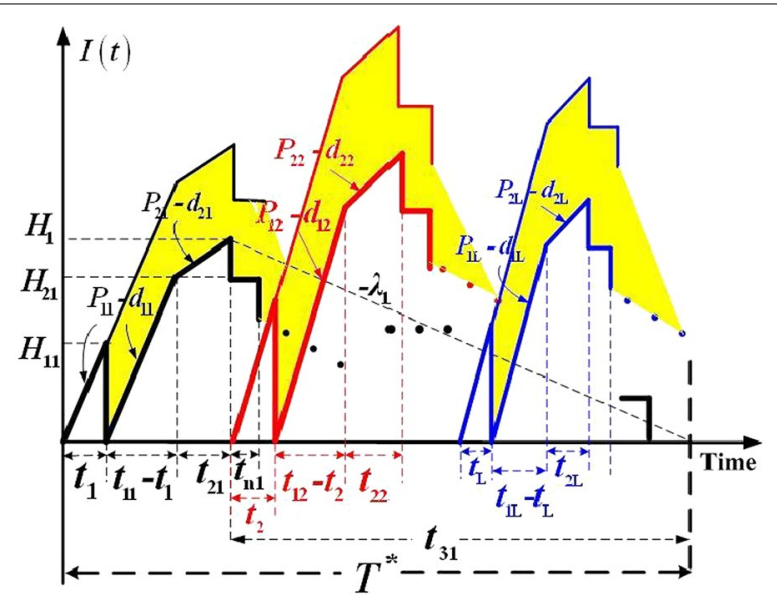

Fig. 2 Expected reduction in producer's inventory holding costs (yellow shaded area) for each product $i$ in the proposed model in comparison with that in Chiu et al. (2013)

quantity) of the finished lot to be shipped to buyers per cycle, $H_{1 i}=$ on-hand inventory in units of product $i$ for meeting buyer's demand during uptime $t_{1 i}$ and reworking time $t_{2 i}, H_{2 i}=$ maximum level of on-hand inventory of product $i$ when the regular production ends, $H_{i}=$ maximum level of on-hand inventory in units of product $i$ when the rework process ends, $t_{i}=$ time required for producing enough items to meet demand of product $i$ during vendor's uptime $t_{1 i}$ and reworking time $t_{2 i}, t_{1 i}=$ production uptime for product $i, t_{2 i}=$ the reworking time for product $i, t_{3 i}=$ the delivery time for product $i, t_{\mathrm{n} i}=$ fixed interval of time between each installment of finished product $i$ being delivered during $t_{3 \mathrm{i}}, I(t)=$ level of on-hand perfect quality items at time $t, I_{\mathrm{S}}(t)_{i}=$ level of on-hand scrap items of product $i$ at time $t, T C\left(Q_{i}\right)=$ total production-inventory-delivery cost per cycle for product $i, \mathrm{E}[T C U(T)]=$ the expected system costs per unit time for $L$ products in the proposed system.

From Fig. 1, the following equations (for $i=1,2, \ldots, L$ ) can be obtained directly:

$$
T=t_{1 i}+t_{2 i}+t_{3 i}=\frac{Q_{i}\left[1-\varphi_{i} E\left(x_{i}\right)\right]}{\lambda_{i}}
$$




$$
\begin{aligned}
& H_{1 i}=\lambda_{i}\left(t_{1 i}+t_{2 i}\right) \\
& H_{2 i}=\left(P_{1 i}-d_{1 i}\right)\left(t_{1 i}-t_{i}\right) \\
& H_{i}=H_{2 i}+\left(P_{2 i}-d_{2 i}\right) t_{2 i} \\
& t_{i}=\frac{H_{1 i}}{P_{1 i}-d_{1 i}}=\frac{\lambda_{i}\left(t_{1 i}+t_{2 i}\right)}{P_{1 i}-d_{1 i}} \\
& t_{1 i}=\frac{Q_{i}}{P_{1 i}}=\frac{H_{1 i}+H_{2 i}}{P_{1 i}-d_{1 i}} \\
& t_{2 i}=\frac{H_{i}-H_{2 i}}{P_{2 i}-d_{2 i}} \\
& t_{3 i}=T-\left(t_{1 i}+t_{2 i}\right)=n t_{n i} \\
& \lambda=\sum_{i=1}^{L} \lambda_{i}
\end{aligned}
$$

The level of on-hand inventory of scrap items in the proposed model is depicted in Fig. 3 and the following equations (for $i=1,2, \ldots, L$ ) can be obtained:

$$
\begin{aligned}
& t_{2 i}=\frac{x_{i} Q_{i}}{P_{2 i}} \\
& d_{1 i} t_{1 i}=x_{i} Q_{i}
\end{aligned}
$$

The variable holding cost for finished items of product $i$ during delivery time $t_{3 i}$ are

$$
h_{i}\left(\frac{n-1}{2 n}\right) H_{i} t_{3 i}
$$

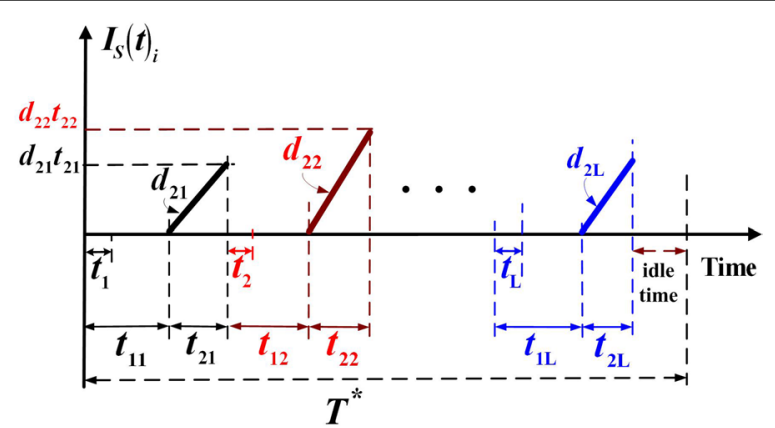

Fig. 3 On-hand inventory of scrap items in the proposed multi-item production system with rework failures and a cost reduction distribution policy 
The fixed and variable transportation costs for product $i$ per cycle are

$$
(n+1) K_{1 i}+C_{\mathrm{T} i} Q_{i}
$$

The production-inventory-delivery cost per cycle for $L$ products comprises the setup cost, the variable manufacturing, reworking, and disposal costs (Fig. 3), the fixed and variable shipping cost, the holding cost during $t_{1 \mathrm{i}}, t_{2 \mathrm{i}}$, and $t_{3 i}$. Therefore, $T C\left(Q_{\mathrm{i}}\right)$ becomes

$\sum_{i=1}^{L} T C\left(Q_{i}\right)$

$=\sum_{i=1}^{L}\left\{\begin{array}{c}K_{i}+C_{i} Q_{i}+C_{\mathrm{R} i}\left(x_{i} Q_{i}\right)+C_{\mathrm{Si}}\left(\varphi_{i} x_{i} Q_{i}\right)+(n+1) K_{1 i}+C_{\mathrm{T} i} Q_{i}\left(1-\varphi_{i} x_{i}\right)+h_{1 i}\left[\frac{d_{1 i} t_{1 i}}{2}\left(t_{2 i}\right)\right] \\ +h_{i}\left[\frac{H_{1 i}}{2}\left(t_{i}\right)+\frac{H_{2 i}}{2}\left(t_{1 i}-t_{i}\right)+\frac{H_{2 i}+H_{i}}{2}\left(t_{2 i}\right)+\frac{d_{1 i} t_{1 i}}{2}\left(t_{1 i}\right)+\left(\frac{n-1}{2 n}\right) H_{i} t_{3 i}\right]\end{array}\right\}$

Because the defective rate $x$ is assumed to be a random variable with a known probability density function, in order to take the randomness of $x$ into account, the expected value of $x$ is used in this study. By substituting all parameters from Eqs. (1) to (13) in Eq. (14), and with further derivations the expected $\mathrm{E}[T C U(T)]$ can be obtained as follows:

$E[T C U(T)]$

$$
=\sum_{i=1}^{L}\left\{\begin{array}{r}
\frac{C_{i} \lambda_{i}}{\left[1-\varphi_{i} E\left[x_{i}\right]\right]}+\frac{K_{i}}{T}+C_{\mathrm{R} i} \lambda_{i}\left[\frac{E\left[x_{i}\right]}{\left[1-\varphi_{i} E\left[x_{i}\right]\right]}\right]+C_{\mathrm{Si}} \lambda_{i}\left[\frac{\varphi_{i} E\left[x_{i}\right]}{\left[1-\varphi_{i} E\left[x_{i}\right]\right]}\right]+C_{T i} \lambda_{i}+\frac{(n+1) K_{1 i}}{T} \\
+\frac{h_{i} T \lambda_{i}^{2}}{2} \frac{1}{\left[1-\varphi_{i} E\left[x_{i}\right]\right]^{2}}\left\{\begin{array}{r}
\lambda_{i}\left[\frac{1}{P_{1 i}}+\frac{E\left[x_{i}\right]}{P_{2 i}}\right]^{2}\left[\frac{2 \lambda_{i}}{P_{1 i}\left(1-E\left[x_{i}\right]\right)}\right]-\frac{E\left[x_{i}\right]}{P_{2 i}}\left[\frac{1}{P_{1 i}}-\left[1-E\left[x_{i}\right]\right]\right] \\
+\frac{1}{P_{1 i}}+\left(1-\frac{1}{n}\right)\left[1-\varphi_{i} E\left[x_{i}\right]\right]\left[\frac{\left[1-\varphi_{i} E\left[x_{i}\right]\right]}{\lambda_{i}}-\frac{2}{P_{1 i}}-\frac{E\left[x_{i}\right]}{P_{2 i}}\right] \\
-\left(1+\frac{1}{n}\right)\left[\lambda_{i}\left[\frac{1}{P_{1 i}}+\frac{E\left[x_{i}\right]}{P_{2 i}}\right]^{2}\right]
\end{array}\right\} \\
+\frac{h_{1 i} T \lambda_{i}^{2}}{2 P_{2 i}} \frac{E\left(x_{i}\right)^{2}}{\left[1-\varphi_{i} E\left(x_{i}\right)\right]^{2}}
\end{array}\right\}
$$

Let

$$
\begin{aligned}
& E_{0 i}=\frac{1}{1-\varphi_{i} E\left[x_{i}\right]} ; E_{1 i}=\frac{E\left[x_{i}\right]}{1-\varphi_{i} E\left[x_{i}\right]} ; E_{2 i}=\left[\frac{1}{P_{1 i}}+\frac{E\left[x_{i}\right]}{P_{2 i}}\right] \\
& E_{3 i}=\frac{2 \lambda_{i}}{P_{1 i}\left[1-E\left[x_{i}\right]\right]} ; E_{4 i}=\left[1-\varphi_{i} E\left[x_{i}\right]\right]\left[\frac{\left[1-\varphi_{i} E\left[x_{i}\right]\right]}{\lambda_{i}}-\frac{2}{P_{1 i}}-\frac{E\left[x_{i}\right]}{P_{2 i}}\right] .
\end{aligned}
$$

Then Eq. (15) becomes

$\operatorname{E}[T C U(T)]$

$$
=\sum_{i=1}^{L}\left\{\begin{array}{c}
C_{i} \lambda_{i} E_{0 i}+\frac{K_{i}}{T}+C_{\mathrm{Ri}} \lambda_{i} E_{1 i}\left[\frac{E\left[x_{i}\right]}{\left[1-\varphi_{i} E\left[x_{i}\right]\right]}\right]+C_{S i} \lambda_{i} \varphi_{i} E_{1 i}+C_{T i} \lambda_{i}+\frac{(n+1) K_{1 i}}{T}+\frac{h_{1 i} T \lambda_{i}^{2} E_{1 i}^{2}}{2 P_{2 i}} \\
+\frac{h_{i} T \lambda_{i}^{2}}{2}\left\{\lambda_{i} E_{2 i}^{2} E_{3 i}-\frac{E\left[x_{i}\right]}{P_{2 i}}\left[\frac{1}{P_{1 i}}-\left[1-E\left[x_{i}\right]\right]\right]+\frac{1}{P_{1 i}}+\left(1-\frac{1}{n}\right) E_{4 i}-\left(1+\frac{1}{n}\right) \lambda_{i} E_{2 i}^{2}\right\}
\end{array}\right\}
$$




\section{Derivation of the optimal cycle time}

Before derivation of the optimal common production cycle time $T^{*}$, one should prove that the expected cost function $\mathrm{E}[T C U(T)]$ is convex. By differentiating $\mathrm{E}[T C U(T)]$ with respect to $T$ gives the following first and second derivatives:

$$
\begin{aligned}
& \frac{d E[T C U(T)]}{d T} \\
& =\sum_{i=1}^{L}\left\{\begin{array}{l}
-\frac{K_{i}}{T^{2}}-\frac{(n+1) K_{1 i}}{T^{2}}+\frac{h_{1 i} \lambda_{i}^{2} E_{1 i}^{2}}{2 P_{2 i}} \\
+\frac{h_{i} \lambda_{i}^{2}}{2}\left\{\lambda_{i} E_{2 i}^{2} E_{3 i}-\frac{E\left[x_{i}\right]}{P_{2 i}}\left[\frac{1}{P_{1 i}}-\left[1-E\left[x_{i}\right]\right]\right]+\frac{1}{P_{1 i}}+\left(1-\frac{1}{n}\right) E_{4 i}-\left(1+\frac{1}{n}\right) \lambda_{i} E_{2 i}^{2}\right\}
\end{array}\right\} \\
& \quad \frac{d^{2} E[T C U(T)]}{d T^{2}}=\sum_{i=1}^{L}\left\{\frac{2\left[K_{i}+(n+1) K_{1 i}\right]}{T^{3}}\right\}
\end{aligned}
$$

It can be seen that Eq. (19) is positive, since $K_{\dot{p}} n, K_{1 \mathrm{i}}$, and $T$ are all positive. Because the second derivative of $E[T C U(T)]>0$, one confirms that $E[T C U(T)]$ is convex for all $T$ different from zero. It follows that by letting the first derivative of $E[T C U(T)]=0$, one can derive the optimal common production cycle time $T^{*}$. Let

$\frac{d E[T C U(T)]}{d T}$

$=\sum_{i=1}^{L}\left\{\begin{array}{l}-\frac{K_{i}}{T^{2}}-\frac{(n+1) K_{1 i}}{T^{2}}+\frac{h_{1 i} \lambda_{i}^{2} E_{1 i}^{2}}{2 P_{2 i}} \\ +\frac{h_{i} \lambda_{i}^{2}}{2}\left\{\lambda_{i} E_{2 i}^{2} E_{3 i}-\frac{E\left[x_{i}\right]}{P_{2 i}}\left[\frac{1}{P_{1 i}}-\left[1-E\left[x_{i}\right]\right]\right]+\frac{1}{P_{1 i}}+\left(1-\frac{1}{n}\right) E_{4 i}-\left(1+\frac{1}{n}\right) \lambda_{i} E_{2 i}^{2}\right\}\end{array}\right\}=0$

or

$\frac{1}{T^{2}} \sum_{i=1}^{L}\left[K_{i}+(n+1) K_{1 i}\right]=\sum_{i=1}^{L} \lambda_{i}^{2}\left\{\frac{h_{1 i} E_{1 i}^{2}}{2 P_{2 i}}+\frac{h_{i}}{2}\left[\begin{array}{r}\lambda_{i} E_{2 i}^{2} E_{3 i}-\frac{E\left[x_{i}\right]}{P_{2 i}}\left[\frac{1}{P_{1 i}}-\left[1-E\left[x_{i}\right]\right]\right] \\ +\frac{1}{P_{1 i}}+\left(1-\frac{1}{n}\right) E_{4 i}-\left(1+\frac{1}{n}\right) \lambda_{i} E_{2 i}^{2}\end{array}\right]\right\}$

Therefore, one has $T^{*}$ as follows:

$$
T^{*}=\sqrt{\frac{2 \sum_{i=1}^{L}\left[K_{i}+(n+1) K_{1 i}\right]}{\sum_{i=1}^{L} \lambda_{i}^{2}\left\{\frac{h_{1 i} E_{1 i}^{2}}{P_{2 i}}+h_{i}\left[\lambda_{i} E_{2 i}^{2} E_{3 i}-\frac{E\left[x_{i i}\right]}{P_{2 i}}\left[\frac{1}{P_{1 i}}-\left[1-E\left[x_{i}\right]\right]\right]+\frac{1}{P_{1 i}}+\left(1-\frac{1}{n}\right) E_{4 i}-\left(1+\frac{1}{n}\right) \lambda_{i} E_{2 i}^{2}\right]\right\}}}
$$

\section{Capacity and setup time effects on the optimal cycle time}

Generally speaking, setup time is relatively short in comparison with uptime. But, if the setup time becomes a factor, one has to ensure that the cycle length is long enough to account for the setup, production, and reworking times of $L$ products (Nahmias 2009). Let $S_{i}$ denote the production setup time for product $i$, the Eq. (23) must hold.

$$
\sum_{i=1}^{L}\left[S_{i}+\left(Q_{i} / P_{1 i}\right)+\left(x_{i} Q_{i} / P_{2 i}\right)\right]<T
$$


Substituting Eq. (1) in Eq. (23) one has

$$
T>\frac{\sum_{i=1}^{L} S_{i}}{1-\sum_{i=1}^{L}\left(\left(\lambda_{i} / P_{1 i}\right)+\left(x_{i} \lambda_{i} / P_{2 i}\right)\right)}=T_{\min }
$$

Therefore, when setup time becomes a significant factor in production planning, one must choose the optimal common cycle length from the maximum of $\left[T^{*}, T_{\min }\right]$.

\section{Numerical example}

With the purpose of easing the comparison efforts for readers, this section uses the same example as in Chiu et al. (2013) to demonstrate the proposed research result. Reconsider a production plan of producing five different items on a single machine in sequence under a common cycle time policy. Annual demand rates $\lambda_{i}$ for these five items are 3000, $3200,3400,3600$, and 3800, respectively. The production rates $P_{1 \mathrm{i}}$ are 58,000; 59,000; 60,$000 ; 61,000$ and 62,000 , respectively. During individual production process, there are random nonconforming rates $x_{i}$ for each item and they follow Uniform distribution over the intervals of $[0,0.05],[0,010],[0,0.15],[0,020]$, and $[0,0.25]$, respectively. All nonconforming items produced go through a rework process at the rates $P_{2 \mathrm{i}}$ of 1800,2000 , 2200,2400 , and 2600 items per year, respectively; with additional unit rework costs $C_{\mathrm{R} i}$ of $\$ 50, \$ 55, \$ 60, \$ 65$, and $\$ 70$, respectively. During the reworking, there are failure-inrework rates $\phi_{\mathrm{i}}$ of $0.05,0.10,0.15,0.20$, and 0.25 , respectively. Additional values of system parameters are given as follows: $K_{i}=$ the setup costs are $\$ 3800, \$ 3900, \$ 4000, \$ 4100$, and $\$ 4200$, respectively, $C_{i}=$ production costs per item are $\$ 80, \$ 90, \$ 100, \$ 110$, and $\$ 120$, respectively, $C_{S i}=$ disposal costs per item are $\$ 20, \$ 25, \$ 30, \$ 35$, and $\$ 40$, respectively, $K_{1 i}=$ fixed costs per delivery are $\$ 1800, \$ 1900, \$ 2000, \$ 2100$, and $\$ 2200$, respectively, $C_{\mathrm{T} i}=$ unit transportation costs are $\$ 0.1, \$ 0.2, \$ 0.3, \$ 0.4$, and $\$ 0.5$, respectively, $n=$ number of shipments per cycle, it is assumed to be a constant 3 (i.e., $n+1=4$ ),

$h_{i}=$ unit holding costs are $\$ 10, \$ 15, \$ 20, \$ 25$, and $\$ 30$, respectively, $h_{1 i}=$ holding costs per reworked item are $\$ 30, \$ 35, \$ 40, \$ 45$, and $\$ 50$, respectively.

The optimal common cycle time $T^{*}=0.7279$ (years) can be obtained by applying Eq. (22). Total expected system costs $\mathrm{E}\left[T C U\left(T^{*}\right)\right]=\$ 2,013,956$ can also be obtained from computation of Eq. (15). Variation of mean defective rate and mean failure-inrework rate effects on the expected system cost $E[T C U(T)]$ is illustrated in Fig. 4. It is noted that as mean defective rate increases the $\mathrm{E}[T C U(T)]$ increases significantly, and as mean failure-in-rework rate increases the system cost $\mathrm{E}[T C U(T)]$ increases slightly.

As stated earlier, the proposed model aims at reducing vendor's inventory holding cost for each product $i$ during the production cycle. As a result from this numerical example, the percentage of overall holding cost reduction is $24.7 \%$ (i.e., from $\$ 109,476$ (Chiu et al. 2013) down to $\$ 82,431$ ). Figure 5 demonstrates the percentage of holding cost reduction for five different products, respectively as compared to that of Chiu et al's work (where n-delivery policy is adopted).

In summary, the proposed study realizes a significant system cost savings of $\$ 56,358$ (i.e., $\$ 2,070,314-\$ 2,013,956)$ or $16.09 \%$ of other system interrelated costs (i.e., $\mathrm{E}[T C U(T)]-\lambda C$, which is the expected system cost excludes variable manufacturing cost). 


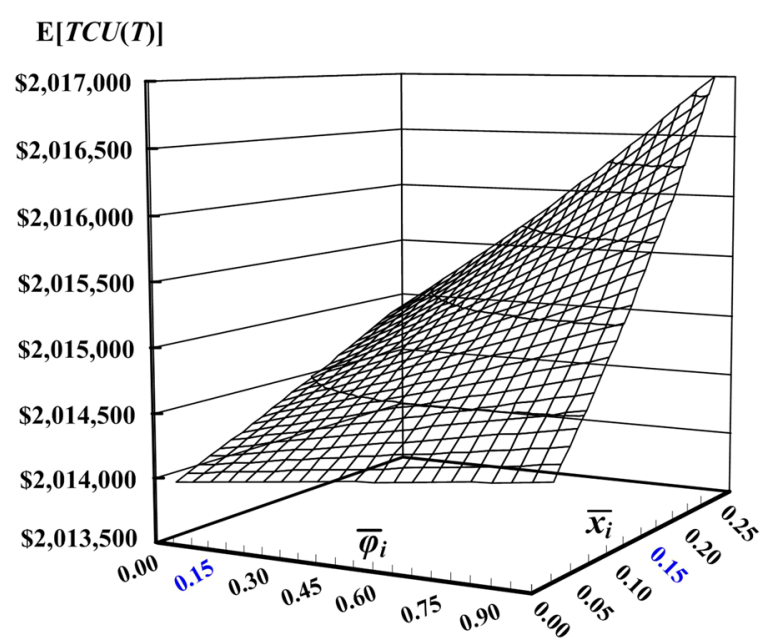

Fig. 4 Variation of mean defective rate and mean failure-in-rework rate effects on the expected system cost $\mathrm{E}[\mathrm{TCU}(T)]$

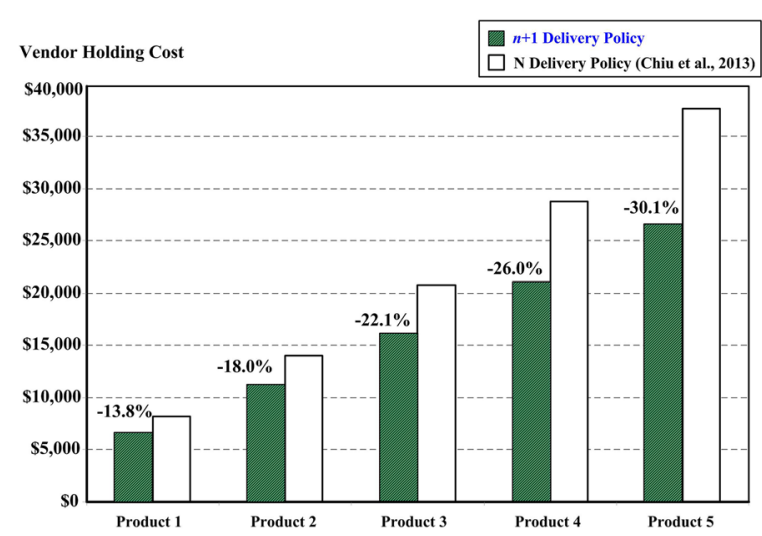

Fig. 5 Percentage of reduction in producer's inventory holding costs for five different products in example, respectively

\section{Conclusions}

With an aim at reducing producer's inventory cost as well as minimizing the expected overall system costs per unit time, this study incorporating an enhanced $n+1$ product issuing policy into Chiu et al's model (2013), and with the help of mathematical modeling and optimization method a closed-form optimal common production cycle time for the proposed multi-product EMQ model with rework failures was derived. A numerical example is given to demonstrate the applicability of our research result, reveal joint effects of random defective rate and failure-in-rework rate on the optimal policy (refer to Fig. 4), and confirm significant savings in producer's inventory holding cost (Fig. 5). For future study, an interesting topic will be to include the machine breakdown factor into such a multi-product EMQ model. 


\section{Author details}

${ }^{1}$ Department of Industrial Engineering and Management, Chaoyang University of Technology, Taichung 413, Taiwan.

2 Department of Business Administration, Chaoyang University of Technology, Taichung 413, Taiwan.

\section{Acknowledgements}

Authors deeply appreciate Ministry of Science and Technology of Taiwan for supporting this study under grant number: MOST 102-2410-H-324-015-MY2.

\section{Competing interests}

The authors declare that they have no competing interests.

Received: 15 September 2015 Accepted: 29 October 2015

Published online: 05 November 2015

\section{References}

Abdul-Jalbar B, Gutiérrez JM, Sicilia J (2008) Policies for a single-vendor multi-buyer system with finite production rate. Decis Support Syst 46:84-100

Agnihothri SR, Kenett RS (1995) Impact of defects on a process with rework. Eur J Oper Res 80:308-327

Andriolo A, Battini D, Grubbström RW, Persona A, Sgarbossa F (2014) A century of evolution from Harris's basic lot size model: survey and research agenda. Int J Prod Econ 155:16-38

Azzi A, Battini D, Faccio M, Persona A, Sgarbossa F (2014) Inventory holding costs measurement: a multi-case study. Int J Log Manage 25(1):109-132

Banerjee A (1986) A joint economic-lot-size model for purchaser and vendor. Decis Sci 17:292-311

Battini D, Grassi A, Persona A, Sgarbossa F (2010a) Consignment stock inventory policy: methodological framework and model. Int J Prod Res 48(7):2055-2079

Battini D, Gunasekaran A, Faccio M, Persona A, Sgarbossa F (2010b) Consignment stock inventory model in an integrated supply chain. Int J Prod Res 48(2):477-500

Battini D, Persona A, Sgarbossa F (2014) A sustainable EOQ model: theoretical formulation and applications. Int J Prod Econ 149:145-153

Biswas P, Sarker BR (2008) Optimal batch quantity models for a lean production system with in-cycle rework and scrap. Int J Prod Res 46:6585-6610

Caggiano KE, Jackson PL, Muckstadt JA, Rappold JA (2009) Efficient computation of time-based customer service levels in a multi-item, multi-echelon supply chain: a practical approach for inventory optimization. Eur J Oper Res 199:744-749

Chiu YSP, Chang HH (2014) Optimal run time for EPQ model with scrap, rework and stochastic breakdowns: a note. Econ Model 37:143-148

Chiu YSP, Lin HD, Cheng FT, Hwang MH (2013) Optimal common cycle time for a multi-item production system with discontinuous delivery policy and failure in rework. J Sci Ind Res India 72:435-440

Chiu YSP, Wu MF, Cheng FT, Hwang MH (2014) Replenishment lot sizing with failure in rework and an enhanced multishipment policy. J Sci Ind Res India 73:648-652

Federgruen A, Katalan Z (1998) Determining production schedules under base-stock policies in single facility multi-item production systems. Oper Res 46:883-898

Glock CH (2011a) Batch sizing with controllable production rates in a multi-stage production system. Int J Prod Res 49:6017-6039

Glock CH (2011b) A multiple-vendor single-buyer integrated inventory model with a variable number of vendors. Comput Ind Eng 60(1):173-182

Glock CH (2012a) The joint economic lot size problem: a review. Int J Prod Econ 135(2):671-686

Glock CH (2012b) Lead time reduction strategies in a single-vendor-single-buyer integrated inventory model with lot size-dependent lead times and stochastic demand. Int J Prod Econ 136(1):37-44

Glock CH, Grosse EH, Ries JM (2014) The lot sizing problem: a tertiary study. Int J Prod Econ 155:39-51

Grosfeld-Nir A, Gerchak Y (2002) Multistage production to order with rework capability. Manage Sci 48:652-664

Hadley G, Whitin TM (1963) Analysis of Inventory Systems. Prentice-Hall, Englewood Cliffs, New Jersey

Hishamuddin H, Sarker RA, Essam D (2014) A recovery mechanism for a two echelon supply chain system under supply disruption. Econ Model 38:555-563

Jodlbauer H, Reitner S (2012) Optimizing service-level and relevant cost for a stochastic multi-item cyclic production system. Int J Prod Econ 136:306-317

Katsaliaki K, Mustafee N, Kumar S (2014) A game-based approach towards facilitating decision making for perishable products: an example of blood supply chain. Expert Syst Appl 41:4043-4059

Lin GC, Wu A, Gong DC, Huang B, Ma WN (2014) On a multi-product lot scheduling problem subject to an imperfect process with standby modules. Int J Prod Res 52:2243-2257

Muramatsu K, Warman A, Kobayashi M (2013) A near-optimal solution method of multi-item multi-process dynamic lot size scheduling problem. JSME Int J C Mech Sy 46:46-53

Murugan M, Selladurai V (2014) Productivity improvement in manufacturing submersible pump diffuser housing using lean manufacturing system. J Eng Res Kuwait 2:164-182

Nahmias S (2009) Production and operations analysis. McGraw-Hill Co., Inc., New York 
Rodger JA (2014) Application of a fuzzy feasibility Bayesian probabilistic estimation of supply chain backorder aging, unfilled backorders, and customer wait time using stochastic simulation with Markov blankets. Expert Syst Appl 41:7005-7022

Rosenblatt MJ, Finger N (1983) Application of a grouping procedure to a multi-item production system. Int J Prod Res 21:223-229

Safaei M (2014) An integrated multi-objective model for allocating the limited sources in a multiple multi-stage lean supply chain. Econ Model 37:224-237

Sana SS, Chedid JA, Navarro KS (2014) A three layer supply chain model with multiple suppliers, manufacturers and retailers for multiple items. Appl Math Comput 229:139-150

Silver EA, Pyke DF, Peterson R (1998) Inventory management and production planning and scheduling. Wiley, New York Swenseth RS, Godfrey RM (2002) Incorporating transportation costs into inventory replenishment decisions. Int J Prod Econ $77: 113-130$

Taft EW (1918) The most economical production lot. Iron Age 101:1410-1412

Wee HM, Wang WT, Kuo TC, Cheng YL, Huang YD (2014) An economic production quantity model with non-synchronized screening and rework. Appl Math Comput 233:127-138

Wu MF, Chiu YSP, Sung PC (2014) Optimization of a multi-product EPQ model with scrap and an improved multi-delivery policy. J Eng Res Kuwait 2:103-118

\section{Submit your manuscript to a SpringerOpen ${ }^{\circ}$} journal and benefit from:

- Convenient online submission

- Rigorous peer review

- Immediate publication on acceptance

- Open access: articles freely available online

- High visibility within the field

- Retaining the copyright to your article

Submit your next manuscript at $\boldsymbol{s p r i n g e r o p e n . c o m ~}$ 